(c) 2020, The Authors. Published by FASS Inc. and Elsevier Inc. on behalf of the American Dairy Science Association ${ }^{\circledR}$. This is an open access article under the CC BY-NC-ND license (http://creativecommons.org/licenses/by-nc-nd/4.0/).

\title{
Characterization of the colostrum and transition milk proteomes from primiparous and multiparous Holstein dairy cows
}

\author{
M. J. Fahey, ${ }^{1}$ A. J. Fischer, ${ }^{2}$ M. A. Steele, ${ }^{2,3 *}$ 이 and S. L. Greenwood ${ }^{1 *} \circledast$ \\ ${ }^{1}$ Department of Animal and Veterinary Sciences, University of Vermont, Burlington 05405 \\ ${ }^{2}$ Department of Animal Biosciences, University of Guelph, ON, Canada, N1G 2W1 \\ ${ }^{3}$ Department of Agriculture, Food and Nutritional Science, Edmonton, University of Alberta, Canada, T6G 2P5
}

\begin{abstract}
Colostrum plays a vital role in the nutrition, development, and immunity of a newborn calf. This study aimed to characterize the protein profile of colostrum and to identify changes in the colostrum proteome across parity during the transition to mature milk. Colostrum and transition milk samples were collected at milkings 1, 2, 4, and 14 after calving from multiparous $(\mathrm{n}=10)$ and primiparous cows $(\mathrm{n}=10)$. Samples were skimmed, fractionated, and enriched before analysis for low-abundance proteins by liquid chromatography-tandem mass spectroscopy (LC-MS/MS). Changes in protein abundances were analyzed using PROC MIXED in SAS (SAS Institute Inc., Cary, NC) with determination of the adaptive false discovery rate adjustment using a MULTTEST procedure to identify effects of parity $(\mathrm{P})$, milking number $(\mathrm{MN})$, and their interaction $(\mathrm{MN} \times \mathrm{P})$. We identified 86 proteins through LC-MS/MS, including 3 low-abundance proteins that were affected by $\mathrm{P}$, 78 that were affected by $\mathrm{MN}$, and 36 affected by $\mathrm{MN} \times \mathrm{P}$. Prominent ontological groupings of proteins affected by MN included defense or immunity proteins, such as immunoglobulins. Proteins involved in the plasminogen activating cascade and more broadly, blood coagulation, were affected by $\mathrm{MN} \times \mathrm{P}$. The results of this study add to increasing knowledge of the colostrum and transition milk proteomes, and this is the first study to find evidence of different abundances of these proteins when examined across $\mathrm{P}, \mathrm{MN}$, and $\mathrm{MN} \times \mathrm{P}$. These findings aid in the identification of potential milk protein biomarkers for mammary health during the early postpartum period.
\end{abstract}

Key words: LC-MS/MS, low-abundance milk protein, whey

\footnotetext{
Received June 11, 2019.

Accepted October 2, 2019.

*Corresponding authors: masteele@uoguelph.ca and sabrina .greenwood@uvm.edu
}

\section{INTRODUCTION}

Colostrum and milk secretions during the transition from colostrum to mature milk, called transition milk, are the first mammary secretions at the onset of lactation and can have important effects on calf health. For the calf, colostrum and transition milk provide crucial nutrients for survival and immunity through passive transfer during the first days of life (Weaver et al., 2000). Although colostral IgG content has historically been perceived as the most important factor determining colostrum quality, recent advances in proteomics also highlight the dynamic nature of the colostrum and transition milk proteomes, leading to identification of additional milk proteins that may have important bioactive properties for the calf (Zhang et al., 2015). Le et al. (2011) reported a $74 \%$ overlap between the colostrum and mature milk (collected at approximately 90 DIM) proteomes and suggested that the proteomes from these 2 secretions are largely consistent; however, the authors did report differential regulation of many proteins, confirming a higher presence of several immune-associated proteins in colostrum compared with mature milk, and identifying a higher presence of several bioactive proteins, including lactoferrin, lactoperoxidase, osteopontin, and butyrophilin subfamily 1 member A1, in mature milk. However, the study by Le et al. (2011) did not include biological replicates, which complicates interpretation, because animal variation is known to occur in several these low-abundance milk proteins (Stelwagen et al., 2009). Consequently, Zhang et al. (2015) were the first to complete an in-depth quantitative analysis of dynamic shifts across bovine colostrum, transition milk, and mature milk proteomes, through repeated sampling of the same 4 animals, collecting samples from d 0 to 9 after calving. Of the 208 proteins quantified in their study, almost $79 \%$ were identified in samples from all 4 cows, whereas the remaining proteins were found only in 1 to 3 of the cows included in the study, highlighting interanimal variability and the need for larger sample sizes. In terms of changes in gene ontology, Zhang et al. (2015) also 
reported higher immune-associated proteins in colostrum compared with milk collected on d 9; however, the authors also reported higher proportions of proteins associated with cell division and proliferation in d-0 samples compared with d-9 samples, with a concurrent increase in enzyme-associated proteins from $\mathrm{d} 0$ to 9 , suggesting that additional bioactive proteins supporting calf gastrointestinal health may be important contributors to colostrum profile and quality. Similarly, Samuel et al. (2017) identified an increase in immuneand growth-associated proteins in exosomes isolated from bovine milk collected from cows at 24,48 , and 72 $\mathrm{h}$ after calving.

For the dam, colostrum and transition milk are the first mammary secretions that occur during a period of intensive mammary upregulation and alveolar activation. In addition to the importance of colostrum to calf development and health, the colostrum and transition milk proteomes could provide insight into dam health and performance during the onset of lactation through identification of milk protein biomarkers. Use of milk proteins as biomarkers to indicate dam energy balance (Lu et al., 2013) and mammary health (Hussein et al., 2018) has been suggested and opens the possibility of collecting a simple milk sample from an individual animal to determine her nutrition and health needs. Hussein et al. (2018) described using serum amyloid A as a more effective biomarker than SCC for subclinical mastitis. Lu et al. (2013) found an association between low energy balance in early-lactation dairy cattle and upregulation of proteins involved in acute inflammatory and immune responses. An extension of this previous literature could be to identify milk proteins that indicate overall mammary functionality during the early-lactation period. Parity number is a nondisease parameter that affects mammary function, and identifying the influence of parity (primi- or multiparous) on both the colostral and the transition milk proteomes could be useful from both a colostrum quality and a mammary biomarker perspective. Koh et al. (2018) successfully used proteomic techniques to identify divergent plasma-associated exosomal protein profiles from high- and low-genetic merit heifers, demonstrating the capacity of MS to identify large numbers of proteins, including understudied proteins, as potential biomarkers related to growth and production potential. To date, no published work has examined the effect of parity on the broad skim milk proteome during the colostral and early-lactation phases using liquid chromatography-tandem mass spectroscopy (LC-MS/MS) proteomic techniques, or whether differences in milk protein profiles emerge due to the collective differences in immune-associated protein secretion and mammary development that we have outlined.
We hypothesized that, in addition to higher abundance of immunoglobulins in colostrum, the low-abundance protein profile will be affected by milking number postpartum. Additional proteins are hypothesized to be affected by parity, particularly those with known roles in mammary function. The objective of this study was to further characterize the low-abundance protein profile of colostrum and transition milk by comparing the abundances and shifts in these proteomes and analyzing the effects of parity $(\mathbf{P})$, milking number $(\mathbf{M N})$ postpartum, and the interaction between parity and milking number $(\mathbf{M N} \times \mathbf{P})$ on the colostrum and transition milk proteomes.

\section{MATERIALS AND METHODS}

\section{Experimental Design and Sample Collection}

Milk samples were collected at Breevliet Farms Ltd. in Alberta, Canada, in accordance with the policies of the University of Alberta Animal Use Committee. A total of 20 healthy Holstein dairy cattle were enrolled in the study, including 10 multiparous (mean parity: $3.1 \pm 0.4 \mathrm{SE}$ ) and 10 primiparous cows. Cows showed no signs of illness for the duration of the trial and did not receive antibiotics. Breevliet Farms Ltd. milked at 0500 and $1600 \mathrm{~h}$ daily, and cows were not administered oxytocin. After a cow calved (dry period length for multiparous cows before calving: $53.4 \pm 3.8$ d), the first milk sample was taken at the nearest milking period in time (0500 or $1600 \mathrm{~h}$ ) after calving (average time to first collection: $5.3 \pm 0.7 \mathrm{~h}$ after parturition). This milk sample was considered milking 1. In total, 4 samples from each of the cows were taken: 1 sample each at milkings 1, 2, 4, and 14 (M1, M2, M4, and M14, respectively), using continuous in-line samplers. Animal information and milk yields for cows at each milking are provided in Supplemental Table S1 (https: //doi.org/10.3168/jds.2019-17094). Samples were snap frozen and stored at $-80^{\circ} \mathrm{C}$ until shipment on dry ice to the University of Vermont (Burlington) for proteomic analysis.

\section{Milk Proteomic Analysis}

Upon arrival at the laboratory, milk samples were stored at $-80^{\circ} \mathrm{C}$ until thawed for fractionation, enrichment, isobaric labeling, and proteomic analysis by LC-MS/MS, as previously described (Tacoma et al., 2017). Briefly, samples were thawed overnight in a $4^{\circ} \mathrm{C}$ refrigerator. A protease inhibitor cocktail (Protease Inhibitor Cocktail for use with mammalian cell and tissue extracts, Sigma-Aldrich, St. Louis, MO) was added according to the manufacturer's instructions, and samples 
were centrifuged at $4,000 \times g$ for $15 \mathrm{~min}$ at $4^{\circ} \mathrm{C}$. The fat layer was then removed, and the centrifugation step was repeated. To deplete caseins, $0.132 \mathrm{~g}$ of calcium dichloride $\left(\mathrm{CaCl}_{2}\right)$ was added, followed by acetic acid (Thermo Fisher Scientific, Fair Lawn, NJ) to acidify the sample to a $\mathrm{pH}$ of 4.3. Ultracentrifugation of the samples was performed for $70 \mathrm{~min}$ at $189,000 \times g$ and $4^{\circ} \mathrm{C}$. The supernatant was collected, transferred into a clean tube, and frozen at $-80^{\circ} \mathrm{C}$ overnight before being lyophilized. The whey powder was reconstituted in PBS. A bicinchoninic assay kit (Pierce Biotechnology, Rockford, IL) was used as per manufacturer's instructions to determine the protein concentration of each sample, using BSA as the standard. An aliquot containing $10 \mathrm{mg}$ of protein was used for enrichment by Proteominer Small-Capacity Protein Enrichment Kits (BioRad Laboratories, Hercules, CA). Protein concentration was again determined by bicinchoninic assay (Pierce Biotechnology). Samples of $100 \mu \mathrm{g}$ each were then digested, and amine-reactive compounds were used to label the peptides using Tandem Mass Tag 10plex Isobaric Labeling Kits (Pierce Biotechnology). The labeled samples were then submitted to the Vermont Genetics Network Core Proteomics Facility (Burlington) for LC-MS/MS analysis.

As outlined in the Vermont Genetics Network Proteomics Facility protocol, peptide identification analyses were performed on the Q-Exactive mass spectrometer coupled to an EASY-nLC ULTRA (Thermo Fisher Scientific). The samples were loaded onto a $100-\mu \mathrm{m} \times$ 190-mm capillary column packed with Halo C18 (2.7 $\mu \mathrm{m}$ particle size, $90 \mathrm{~nm}$ pore size, Michrom Bioresources, Auburn, CA) at a flow rate of $300 \mathrm{~nL} / \mathrm{min}$. The column end was laser pulled to an approximately $3-\mu \mathrm{m}$ orifice and packed with minimal amounts of $5-\mu \mathrm{m}$ Magic C18AQ (Michrom Bioresources) before packing with $3-\mu \mathrm{m}$ particle size chromatographic materials. Peptides were separated then introduced into the mass spectrometer via a nanospray ionization source. Mass spectrometry data were acquired in a data-dependent "Top 10" acquisition mode.

Product ion spectra were searched using SEQUEST and Mascot, implemented on Proteome Discoverer 2.2 (Thermo Fisher Scientific) against a curated Uniprot Bos taurus protein database (3AUP000009136; downloaded on Aug 31, 2017; www.uniprot.org). The 9 raw files (eight 10-plex and one 9-plex) were searched against the database as 1 contiguous input file, yielding 1 result file. The abundances of Tandem Mass Tag-labeled peptides (Pierce Biotechnology) were quantified by setting the peptide abundances in the "universal control" labels as 100 and scaling the abundances in other channels accordingly. Abundance values are pro- vided in Supplemental Table S1 (https://doi.org/10 $.3168 /$ jds.2019-17094).

\section{Statistical Analysis}

Scaled abundance values were analyzed using PROC MIXED of the SAS System for Windows (SAS Institute Inc., Cary, NC). The MODEL statement included the dependent variable of protein and the fixed effects of $\mathrm{P}$, $\mathrm{MN}$, and $\mathrm{MN} \times \mathrm{P}$. A REPEATED statement declared $\mathrm{MN}$ as a repeated measure, assuming an unstructured covariance structure (TYPE $=\mathrm{UN})$, with cow as the subject (random effect). An LSMEANS statement was included, to compute the least squares means of all fixed effects. A PROC MULTTEST procedure was performed to determine the adaptive false discovery rate-adjusted protein abundances for each of the proteins (dependent variables). Gene ontology (GO) profiles of affected proteins (adaptive false discovery rate-adjusted $P$-value $\leq 0.05)$ were determined using the PANTHER Classification System (PANTHER14.0; Thomas et al., 2003; Mi et al., 2010). Identification of uncharacterized proteins within Proteome Discoverer was completed using PANTHER.

\section{RESULTS}

\section{Protein Identification and Cellular Component Analysis}

In total, we characterized 86 proteins in the samples (Table 1). We found that 36 proteins were affected by $\mathrm{MN} \times \mathrm{P}$ and 78 were affected by MN. Thirty-three proteins were affected by both $\mathrm{MN}$ and $\mathrm{MN} \times \mathrm{P}$. Of the 86 identified proteins, 4 were affected by parity: 3 were low-abundance proteins and the fourth was a highabundance casein fragment.

Gene ontological classification highlighted some variation in cellular component analysis across proteins affected by $\mathrm{P}, \mathrm{MN}$, and $\mathrm{MN} \times \mathrm{P}$. Within $\mathrm{P}, \mathrm{MN}$, and $\mathrm{MN} \times \mathrm{P}$, extracellular region proteins were found in the highest proportion when grouped by cellular component, representing $75,39.7$, and $45.7 \%$, respectively, of gene hits against total number of genes in each category (Figure 1).

\section{Proteins Affected by Parity}

Only 3 low-abundance proteins were affected by $\mathrm{P}$ : lactoperoxidase, immunoglobulin $\alpha$ chain $\mathrm{C}$ region, and peptidoglycan recognition protein 1 (Table 1). All of these proteins were identified by GO as being involved in response to stimulus (GO: 0050896). In M4 and M14, 
Fahey et al.: COLOSTRUM AND TRANSITION MILK PROTEOMES

1996

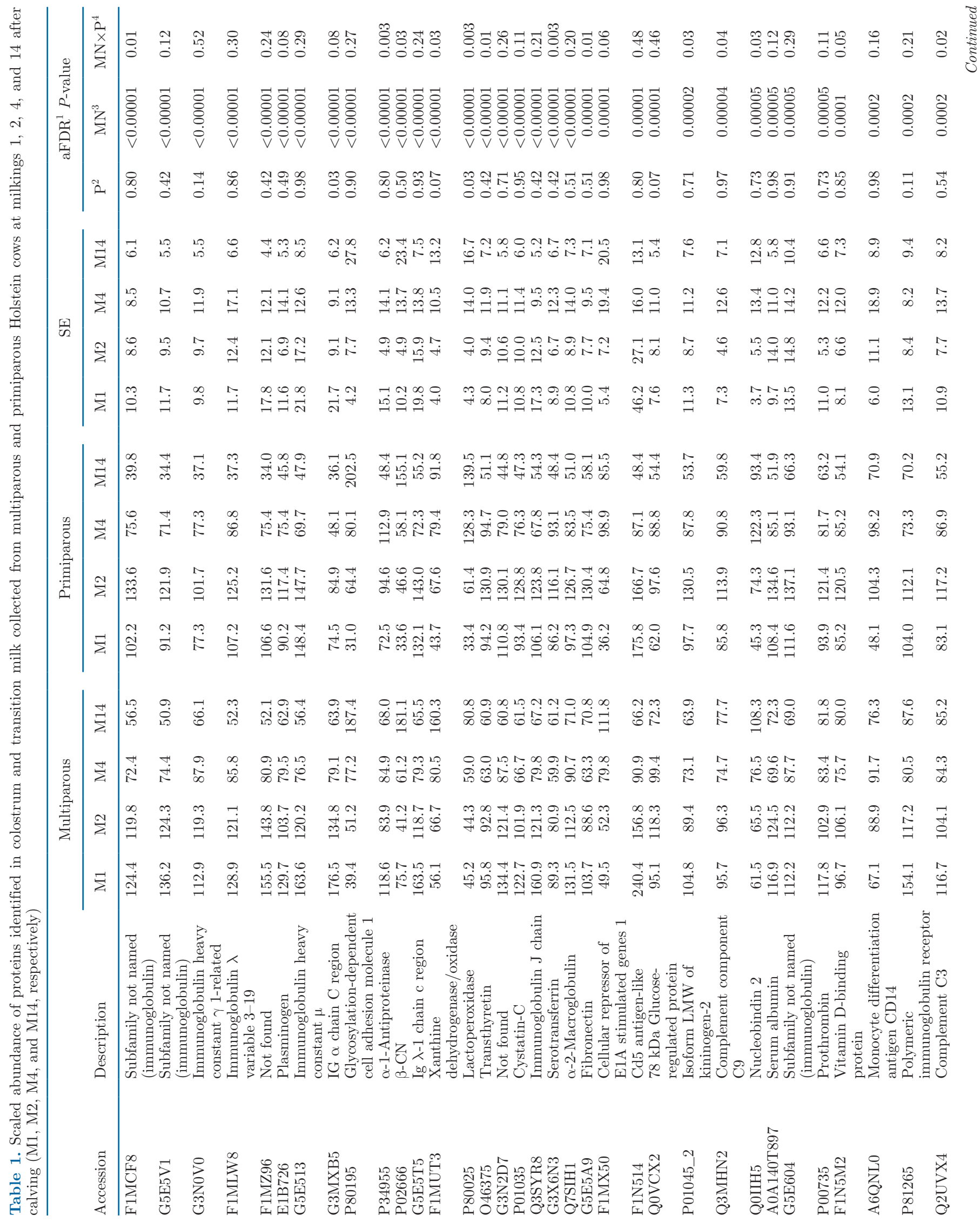




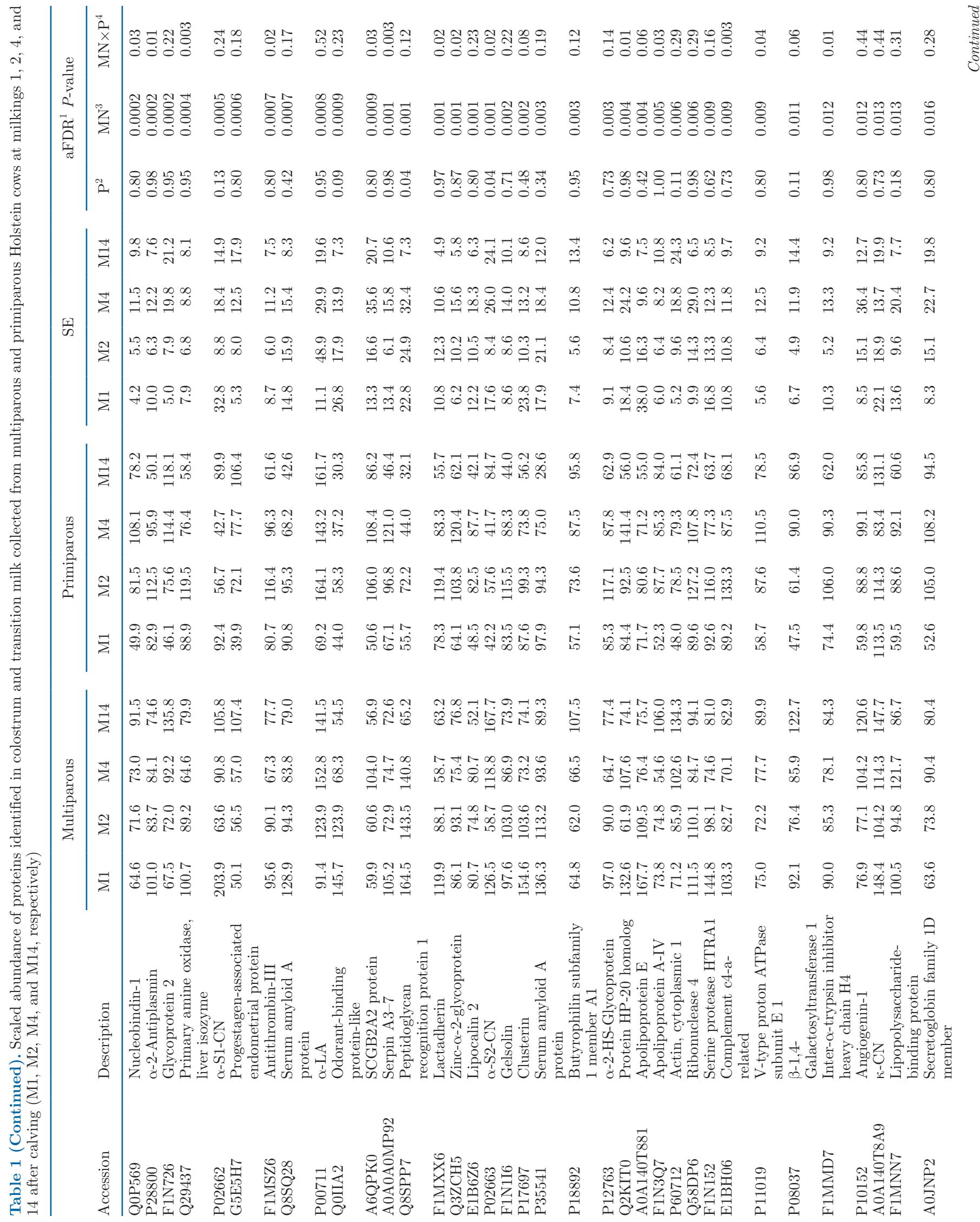


Fahey et al.: COLOSTRUM AND TRANSITION MILK PROTEOMES

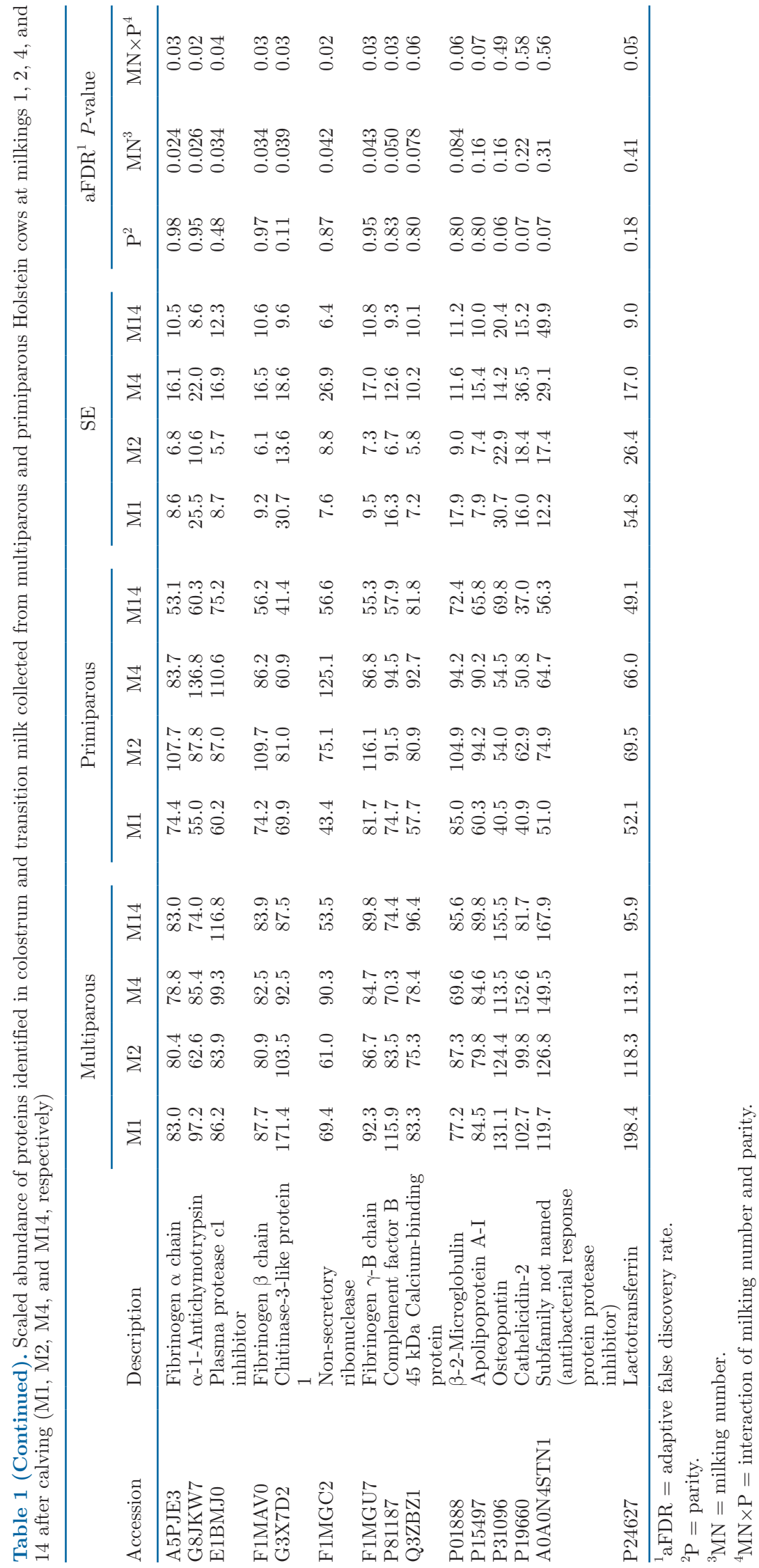




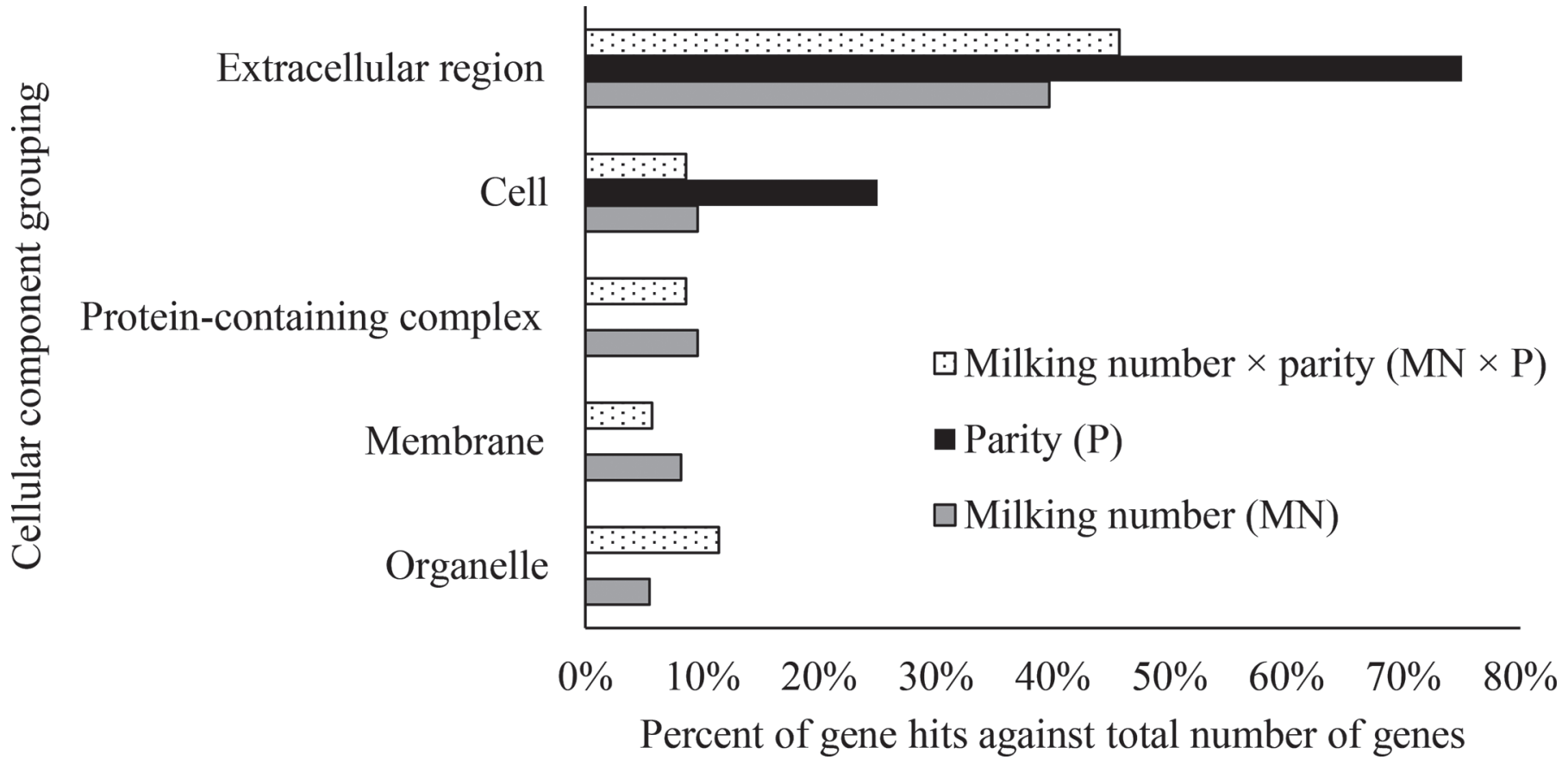

Figure 1. Cellular component analysis of gene ontological classifications of proteins affected by parity (P), milking number (MN), and interaction between milking number and parity $(\mathrm{MN} \times \mathrm{P})$.

the abundance of lactoperoxidase was 2-fold higher in samples from primiparous cows than from multiparous cows. Peptidoglycan recognition protein-1 and IG Alpha chain C region's abundance in M1 were both 2-fold higher in multiparous than in primiparous samples, then decreased from M1 to M2 in multiparous samples, while primiparous samples peaked in abundance.

\section{Proteins Affected by Milking Number}

Of the proteins affected by MN (78 proteins), the primary ontological groupings in molecular function were binding (GO: 0005488, 46.6\%) and catalytic activity (GO: 0003824, 31.5\%; Figure 3). Clusters in biological process included metabolic process (GO: 0008152, $30.1 \%$ ) and response to stimulus (GO: 0050896, 34.2\%; Figure 2). Proteins involved in defense or immunity (PC00090, 13.7\%), such as Complement C3, serum amyloid A protein, and $\alpha-2$-macroglobulin, decreased in abundance after M1 and M2 (Table 1).

\section{Proteins Affected by Parity and Milking Number Interaction}

Of the 86 identified proteins, 36 were affected by $\mathrm{MN} \times \mathrm{P}$, including a large proportion that are involved in binding (GO: 0005488, 57.1\%) and catalytic activity (GO: 0003824, 31.4\%). Similar to proteins affected by
MN, metabolic process (GO: 0008152, 34.3\%) was the most prominent grouping when classified by biological process. Figure 3 depicts the patterns of abundance in proteins involved in the plasminogen-activating cascade that were affected by $\mathrm{MN} \times \mathrm{P}: \alpha$-2-antiplasmin, fibrinogen $\alpha$ chain, fibrinogen $\beta$ chain, and fibrinogen $\gamma \mathrm{B}$ chain. Two other proteins, $\alpha$-1-antiproteinase (A1AP) and antithrombin-III, were identified, in addition to these, under the category of blood coagulation. They followed similar trends to those shown in Figure 3; however, A1AP peaked at M4 instead of M2 in primiparous animals (Table 1 ).

\section{Impact of Milking Number and Parity on Known Bioactive Proteins}

Known bioactive proteins, including lactoperoxidase $(P<0.00001)$, lactadherin $(P=0.001)$, zinc- $\alpha-2-$ glycoprotein $(P=0.001)$, xanthine dehydrogenase/ oxidase $(P<0.00001)$, and butyrophilin subfamily 1 member A1 $(P=0.003)$, were all affected by MN. Lactoperoxidase $(P=0.002)$, lactoferrin $(P=0.05)$, lactadherin $(P=0.02)$, zinc- $\alpha$-2-glycoprotein $(P=0.02)$, and xanthine dehydrogenase/oxidase $(P=0.03)$ were also affected by $\mathrm{MN} \times \mathrm{P}$. Osteopontin was identified in the colostrum and transition milk samples; however, it was not affected by parity $(P=0.06), \mathrm{MN}(P=0.16)$, or $\mathrm{MN} \times \mathrm{P}(P=0.49)$. 
Fahey et al.: COLOSTRUM AND TRANSITION MILK PROTEOMES
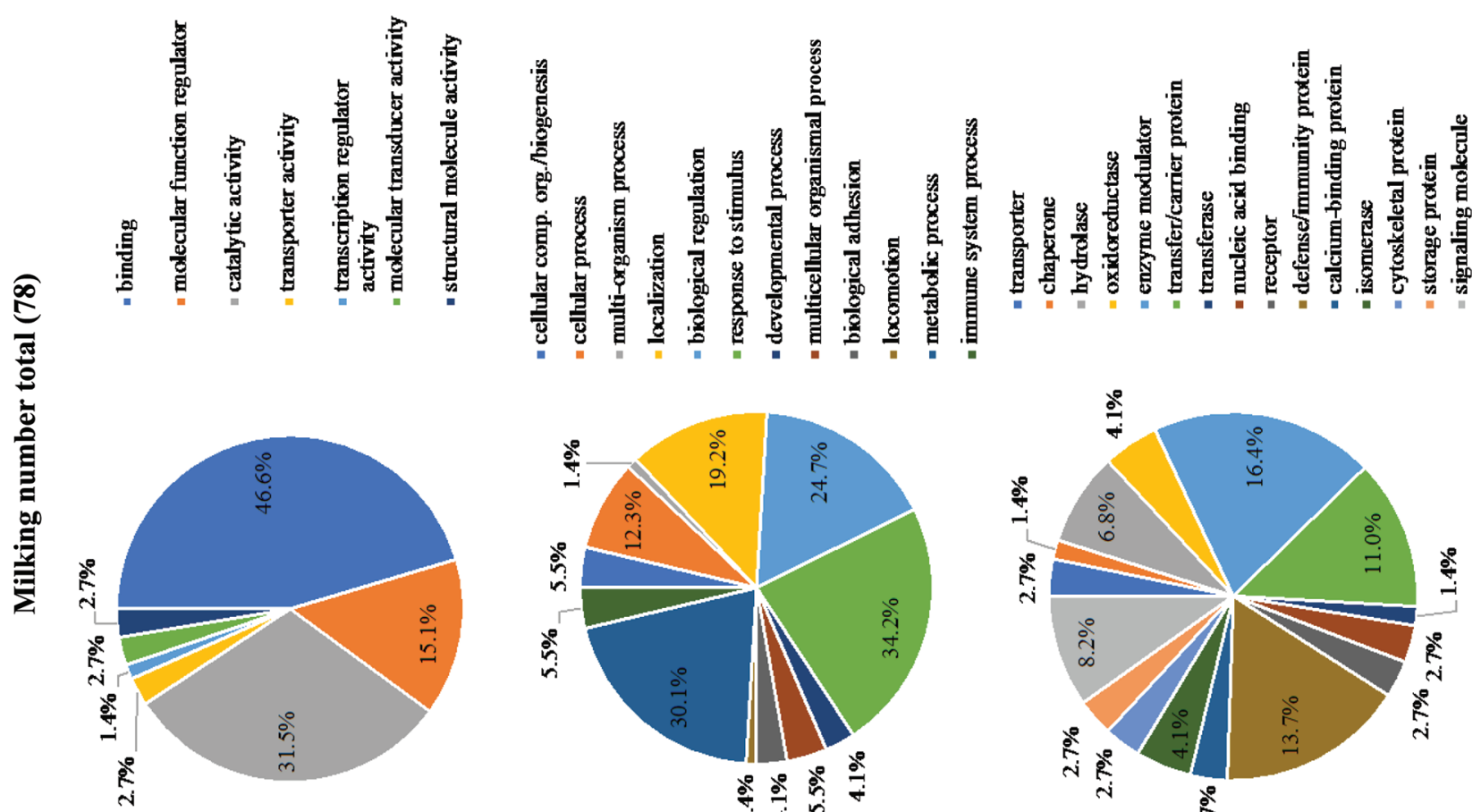

要

它 家的

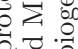

ส․
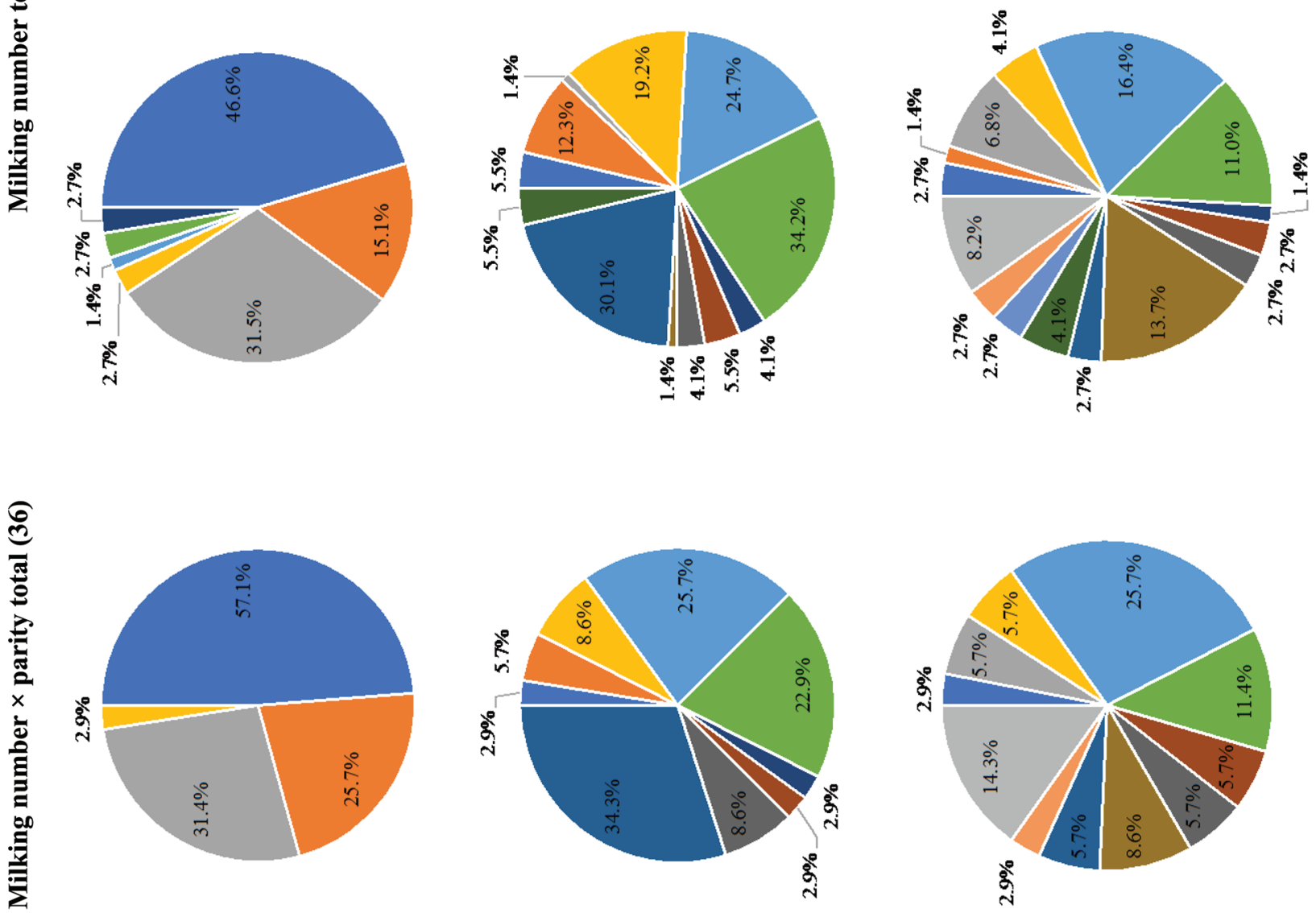

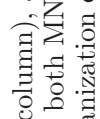

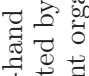

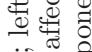

学荧

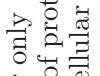

它语

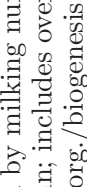

品

光

青专寻

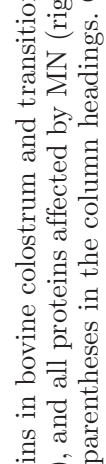
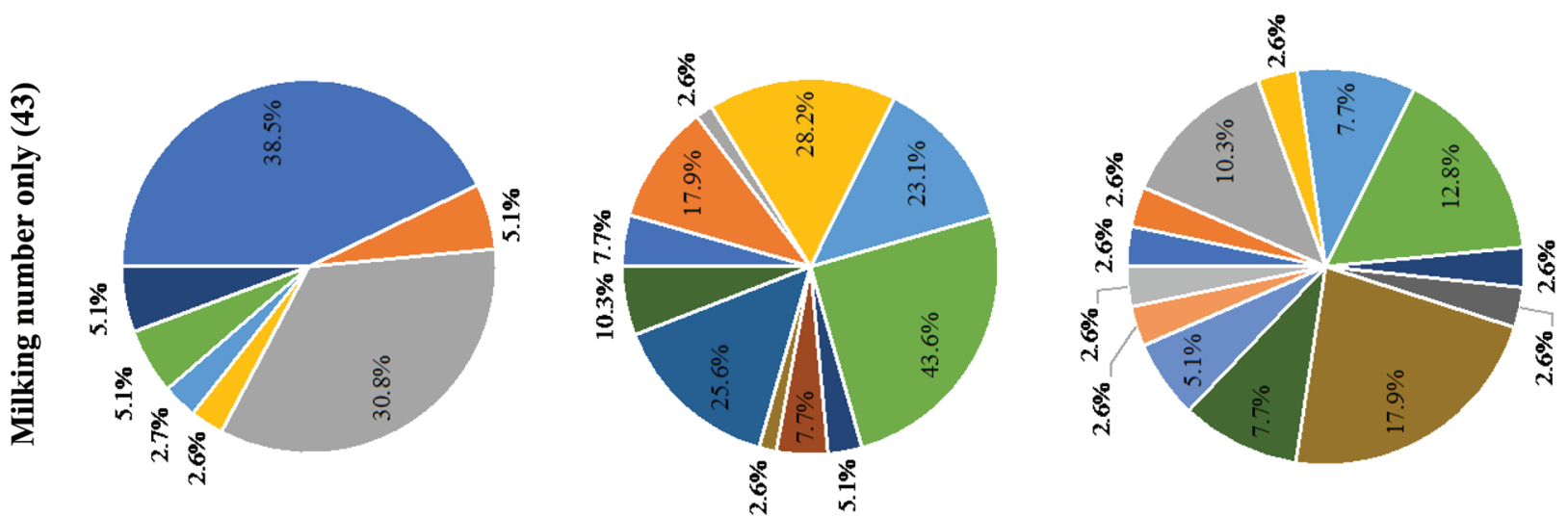

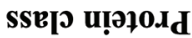

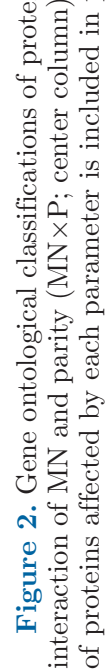




\section{DISCUSSION}

Analytically, completion of proteomic analysis of colostrum and transition milk using repeated sampling and a large number of animals allows us to further confirm previous observations. Furthermore, the use of a high-throughput technique such as LC-MS/MS allows for identification and assessment of a greater number of proteins, including many that have not been widely studied and may not have been optimized for Western blot analysis. Biologically, integration of the current results with physiological responses described in previous literature provides a better understanding of the effects of parity on the milk protein profile and the interaction of parity with milking number postpartum on the colostrum and transition milk proteome. These results are relevant to the industry in that they support the concept that milk proteins do fluctuate in response to physiology; therefore, potential applications include validation of use of a responsive milk protein as a biomarker of mammary functionality at the onset of lacta- tion, or development of additional considerations for colostrum feeding strategies with the knowledge that the colostrum proteome shifts rapidly postpartum and that the proteome is affected by parity of the dam. Characterization of the bioactive profiles of the different colostrum and milk proteomes may also be a pertinent aspect of future preweaned calf health research.

A 2011 study identified 24 proteins whose abundances were upregulated in colostrum compared with mature milk sampled at 3 mo postparturition in the dairy cow (Le et al., 2011). The present study identified 15 of these proteins in both colostrum and transition milk samples. As Le et al. (2011) describe, many of these proteins are antibody and complement components relating to immune system processes. All of the proteins' abundances were affected by $\mathrm{MN}$ in the present study and generally decreased in abundance after their peak in M1 and M2. Interestingly, 8 of these 15 proteins were also significantly affected by $\mathrm{MN} \times \mathrm{P}$ in the present study. Nissen et al. (2017) developed protein rankings and ratios of importance of these proteins in

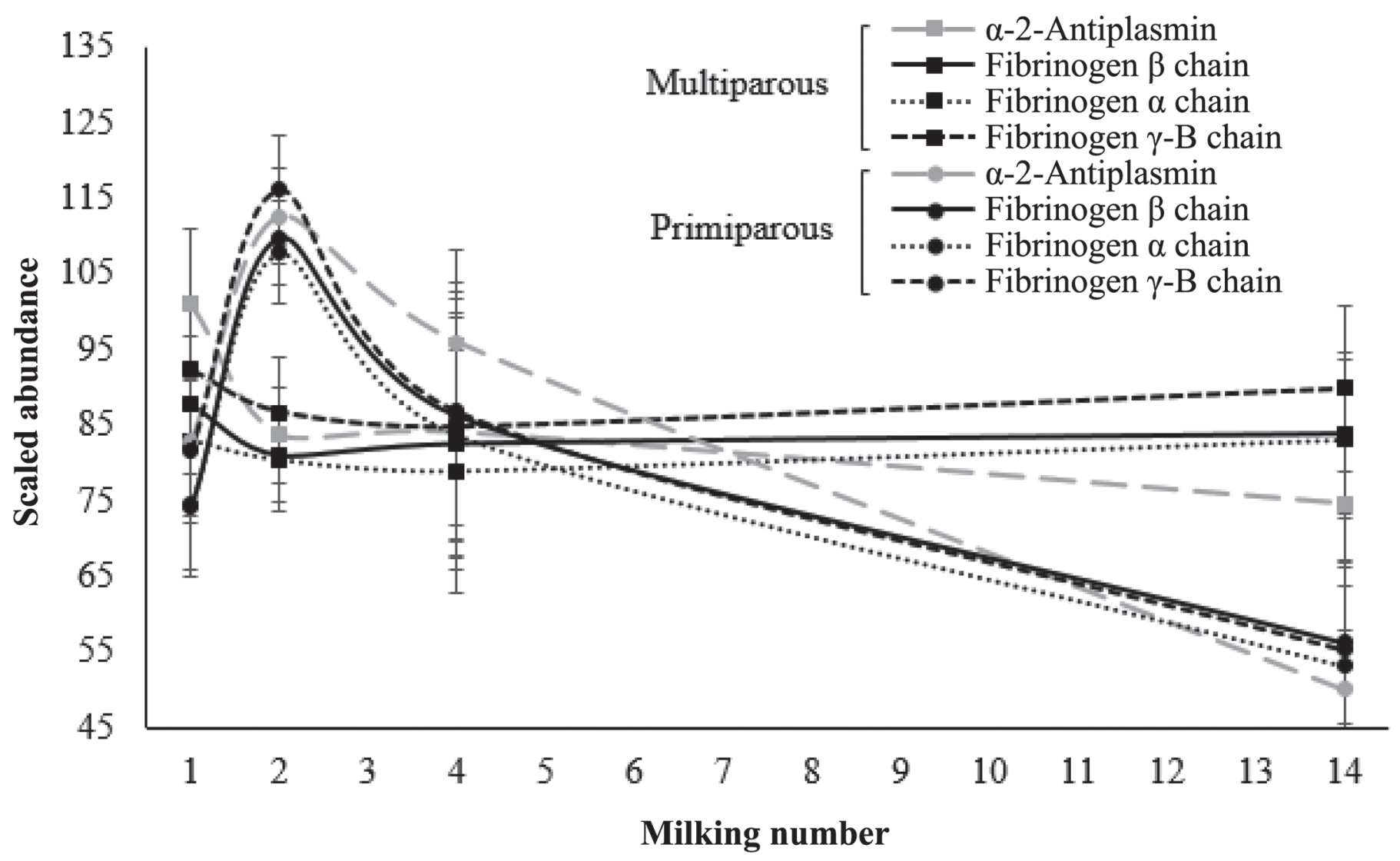

Figure 3. Scaled abundances of low-abundance proteins in colostrum and transition milk samples collected from primiparous and multiparous cows that were affected by the interaction between milking number and parity $(\mathrm{MN} \times \mathrm{P})$ and identified by PANTHER analysis (Thomas et al., 2003; Mi et al., 2010) to be involved in the plasminogen-activating cascade. Abundance values are scaled relative to a universal control (set at 100). Error bars represent SE. 
colostrum and mature milk, and suggested that other low-abundance proteins may be of higher importance in colostrum than immunoglobulins.

Milking number affected the most proteins: $91.8 \%$ of those identified. In agreement with previous studies (Nissen et al., 2012; Reinhardt et al., 2013; Boggs et al., 2016; Tacoma et al., 2016), the majority of the 78 proteins were encompassed within catalytic activity, binding, cellular process, and response to stimulus categories when analyzed by GO. These categories were again dominant when analyzing proteins affected by $\mathrm{MN} \times \mathrm{P}$, in part due to a large overlap between proteins affected by both $\mathrm{MN}$ and $\mathrm{MN} \times \mathrm{P}$. In contrast with previous studies (Nissen et al., 2012; Reinhardt et al., 2013; Boggs et al., 2016; Tacoma et al., 2016), extracellular region was the most encompassing when grouped by cellular component for proteins affected by $\mathrm{P}, \mathrm{MN}$, and $\mathrm{MN} \times \mathrm{P}$ and, as discussed below, is likely a result of the extensive mammary development and upregulation that occurs during the transition period.

\section{Effects of Parity on Antimicrobial-Associated Bioactive Proteins}

The 3 low-abundance proteins affected by $\mathrm{P}$ were peptidoglycan recognition protein 1 , lactoperoxidase, and immunoglobulin $\alpha$ chain $\mathrm{C}$ region, all of which have been identified as having antimicrobial properties. Antimicrobial agents in colostrum have roles in immune and gastrointestinal development of the calf (Le et al., 2011). Immunoglobulins are well known for their role of binding to components of pathogens and targeting them for destruction by the immune system. Le et al. (2011) found that peptidoglycan recognition protein was 1 of 24 whey proteins significantly upregulated in bovine colostrum compared with mature milk, most likely due to its involvement in innate immunity. The research described herein is the first known report identifying a relationship between parity and abundance of this protein in milk. Lactoperoxidase is an enzyme known to be found in bovine colostrum, whose reaction products are bactericidal for some gram-negative and bacteriostatic for some gram-positive microorganisms (Kussendrager and van Hooijdonk, 2000), which is important when considering these results and their effects on calf development in the first week of life. Korhonen (1977) found that lactoperoxidase increased gradually until milking 3 to 4 and afterward steadily decreased, suggesting that ingestion of the dam's milk was important even after the window for passive immunity had passed. The researcher concluded that the risk of microbial infection was reduced in the week following birth, first by passive immunity in the first 24 to $36 \mathrm{~h}$ and then by antimicrobial proteins such as lactoperoxidase in transition milk.
The present study also found that the abundance of lactoperoxidase in transition milk was higher than that of colostrum, in agreement with Korhonen (1977). Interestingly, the abundance of lactoperoxidase was 2-fold higher in samples from primiparous cows compared with samples from multiparous cows in M4 and M14, and previous reports suggest that this higher secretion from primiparous cows compared with multiparous cows may continue for the entire early-lactation period (Isobe et al., 2011).

Immunoglobulin $\alpha$ chain $\mathrm{C}$ region and peptidoglycan recognition protein followed similar trends within P. Their abundance in M1 was over 2-fold higher in multiparous than in primiparous samples. Both proteins sharply decreased from M1 to M2 in multiparous samples, but primiparous samples peaked in abundance in M1 and M2. The significant differences in abundances of these proteins suggests a difference in mammary gland physiology between multiparous and primiparous animals, as proteins are secreted into milk through direct secretion by epithelial cells of the gland, through transport from serum, or through tissue sloughing (Le et al., 2011). The mammary gland of a primiparous animal undergoes dramatic changes, both in puberty and in preparation for lactation, that could explain the differences in protein profiles of their colostrum and transition milk compared with those of multiparous animals. Miller et al. (2006) found that metabolic and secretory activity of mammary gland cells was higher in multiparous animals than in primiparous heifers, due to higher density of secretory cells. The study concluded that although primiparous mammary glands were less dense with secretory cells during the onset of lactation, proliferation of these cells began postparturition in primiparous but not in multiparous animals. The dynamic changes occurring in the mammary gland both before and after parturition may contribute to the changes seen in the low-abundance protein profile. Knowing the bioactive importance of these proteins to the calf, it is of interest to understand whether the proteins in colostrum and transition milk affected by $\mathrm{P}$ have more or less benefit to the calf in higher abundance.

\section{Gene Ontology and Bioactive Profile of Proteins Affected Only by Milking Number}

We found a large overlap in the proteins affected by both $\mathrm{MN}$ and $\mathrm{MN} \times \mathrm{P}$ (33 proteins), but 41 proteins were affected by MN only, a novel finding of this study. The molecular functions, biological processes, and protein class profiles of these proteins were diverse, with 7, 11, and 13 different groupings, respectively (Figure 2 ). Ontological protein classes of defense or immunity (PC00090; 17.9\%), isomerase (PC00135; 7.7\%), and 
hydrolase (PC0012; 10.3\%) were proportionally greater in the proteins affected only by MN compared with all proteins affected by both $\mathrm{MN}$ and $\mathrm{MN} \times \mathrm{P}$ (13.7, 4.1, and $6.8 \%$, respectively; Figure 2). Other ontological protein classes were proportionally smaller or even absent, including calcium-binding proteins (PC00060), nucleic acid-binding proteins (PC00171), signaling molecules (PC00207), and cytoskeletal proteins (PC00085).

Interestingly, low-abundance proteins related to the immune system that were affected uniquely by $\mathrm{MN}$ included serum amyloid A, LPS-binding protein, $\alpha-2-$ macroglobulin, and several immunoglobulins (Table 1 ). The presence of these known bioactive proteins in colostrum and transition milk could be important factors that support calf health (Hernández-Castellano et al., 2014). Immunoglobulins $\lambda-1$ chain $\mathrm{C}$ region, $\alpha$ chain $\mathrm{C}$ region, and $\lambda$ variable $3-19$ all had high abundance in M1 and M2 and thereafter decreased (Table 1 ). These findings are in agreement with other previously published data describing a higher abundance of immunoglobulins postparturition compared with d 9 and beyond (Le et al., 2011; Zhang et al., 2015). It is well understood that the timeline for passive transfer of immunoglobulins from colostrum to calf occurs in the first 24 to $36 \mathrm{~h}$ of the calf's life (Weaver et al., 2000). During this period, immunoglobulins, along with other proteins, are readily taken up by epithelial cells of the GI tract and subsequently provide immediate systemic immunity (Weaver et al., 2000). The observed decreases in immunoglobulins after M1 and M2 coincides with the closure of this absorptive system in the calf.

Although the classes of proteins affected by only MN and not $\mathrm{MN} \times \mathrm{P}$ differed slightly from all those affected by MN (including those affected by MN only and those also affected by $\mathrm{MN} \times \mathrm{P}$ ), their molecular function and biological process profiles were similar. When compared with those affected by $\mathrm{MN} \times \mathrm{P}$, these profiles differed dramatically. The proportion of defense and immunity proteins only affected by $\mathrm{MN}(17.9 \%)$ was double the proportion of those also affected by $\mathrm{MN} \times \mathrm{P} \quad(8.6 \%$; Figure 2). This suggests that more immune-related proteins are affected by just MN than by both $\mathrm{MN}$ and $\mathrm{MN} \times \mathrm{P}$.

\section{Proteins Affected by Milking Number and the Interaction Between Milking Number and Parity}

Apart from the differences in immune-associated proteins discussed above, many other ontological groupings were different when examining proteins affected by $\mathrm{MN}$ only versus those affected by $\mathrm{MN} \times \mathrm{P}$. Proteins associated with localization and biological adhesion processes were proportionally less represented in pro- teins affected by $\mathrm{MN} \times \mathrm{P}$ than in those affected by $\mathrm{MN}$ only (Figure 2). The protein classes affected by $\mathrm{MN} \times \mathrm{P}$ were also less diverse, with only 11 groupings compared with 15 groupings of proteins affected by MN. Despite this seemingly less-diverse profile, 1 grouping was more represented in proteins affected by $\mathrm{MN} \times \mathrm{P}$ : blood coagulation proteins.

Proteins involved in blood coagulation, specifically the plasminogen-activating cascade, have previously been reported in bovine milk ( $\mathrm{Lu}$ and Nielsen, 1993; Precetti et al.,1997) and were also identified in the current study. This finding is novel and could provide an opportunity for development of a biomarker targeted toward cellular function during the early postpartum period. Plasminogen is the zymogen (inactive form) of plasmin, whose general systemic function is to break down blood clots by cleaving fibrin (Precetti et al., 1997). In the mammary gland, plasmin is an extracellular serine protease heavily involved in the process of involution (Green et al., 2006). Involution is the process of mammary gland regression at the end of lactation; however, during lactation, plasminogen has been found necessary for maintenance of mammary gland function (Green et al., 2006).

The present study found 5 low-abundance proteins related to blood coagulation, 4 of which were involved in the plasminogen-activating cascade, in colostrum and transition milk: $\alpha$-2-antiplasmin, $\alpha$-1-antiproteinase, fibrinogen ( $\alpha, \beta$, and $\gamma \mathrm{B}$ chains), and antithrombin-III (Figure 3). $\alpha$-2-Antiplasmin is a direct plasmin inhibitor, whereas fibrinogen is the binding site for plasminogen to then be converted to plasmin (Zwirzitz et al., 2018). All plasminogen-activating cascade proteins peaked in M1 for multiparous cows, whereas primiparous cows peaked in M2 or later and at a slightly higher abundance (Figure 3). Lactoferrin, a well-characterized milk protein, has also recently been linked to a new function of binding plasminogen to prevent activation to plasmin (Zwirzitz et. al., 2018). Interestingly, out of the 86 proteins identified in the present study, lactoferrin was the only protein affected only by $\mathrm{MN} \times \mathrm{P}$. Although its regulatory factors were affected by $\mathrm{MN} \times \mathrm{P}$, plasminogen itself was affected by MN only. Plasminogen peaked at similar abundances in M1 for multiparous animals and M2 for primiparous animals.

Evidence of the importance and regulation of coagulation-associated proteins in the mammary gland is present in previous literature. Green et al. (2006) genetically modified plasminogen-deficient mice and found that they were unable to support the nutritional needs of their litters, measured by complete mortality of offspring. The dysfunction of the mammary gland in plasminogen-deficient mice was thought to be caused by apoptosis-mediated premature involution of secretory 
tissue (Green et al., 2006). A more recent study, using genetically modified mice deficient in a known receptor for plasminogen, found that mammary dysfunction was attributable to a severe decrease in alveologenesis (Miles et al., 2018). As described above, the physiology of lactogenesis in the primiparous cow is different from that of the multiparous cow (Miller et al., 2006). A primiparous cow's first development of the mammary gland begins at puberty, in which, under the control of hormones, ductal development within the fat pad begins (Inman et al., 2015). Secretory alveoli and further ductal development occur during pregnancy (Inman et al., 2015). Vascular and lymphatic tissue intercalate these structures and provide nutrients to the mammary epithelium (Inman et al., 2015). In bovine milk, plasminogen has been shown to be derived from blood plasma, and, further, its most likely route of passage into milk is transcellular via secretory vesicles (Eigel et al., 1979; Silanikove, 2016). Parturition stimulates mammary epithelial cells to begin synthesizing and secreting milk. For multiparous animals, secretory tissue from previous lactations remains, and the process of mammary development, such as alveogenesis, is less dramatic than for primiparous cows (Miller et al., 2006). The observed trend in plasminogen-activating cascade-related proteins may be attributable to the continued proliferation and remodeling of the primiparous animals' mammary gland after parturition. The importance of these proteins in both lactation and involution points toward their ability to serve as a biomarker for mammary function.

\section{CONCLUSIONS}

Exploration of the colostrum and milk proteomes using LC-MS/MS techniques is increasing our understanding of this dynamic fluid; however, our understanding of the physiological influences that affect the proteome is relatively weak. This is one of the first known publications to use these proteomic techniques to identify the effect of parity on the proteome. Of the 86 proteins identified using proteomic techniques in the current study, 78 proteins were affected by MN, 3 lowabundance proteins were affected by $\mathrm{P}$, and 36 proteins were affected by $\mathrm{MN} \times \mathrm{P}$. Gene ontology classification of proteins affected by $\mathrm{MN}, \mathrm{P}$, and $\mathrm{MN} \times \mathrm{P}$ showed some divergence. Parity influenced the proteins involved in the biological response to stimulus, whereas proteins affected by $\mathrm{MN}$ and $\mathrm{MN} \times \mathrm{P}$ were predominantly those with known molecular functions associated with binding and catalytic activity. Proteins involved in the plasminogen-activating cascade were a cluster of proteins differentially affected by $\mathrm{MN} \times \mathrm{P}$. Cumulatively, these observed differences in the characterized colostrum and transition milk proteomes due to parity demonstrate that differences in mammary secretion are evident at the onset of lactation, and further research is needed to identify whether these proteins could be used as biomarkers of mammary function, or whether milk containing these different proteomes may affect the health of preweaned calves.

\section{ACKNOWLEDGMENTS}

The authors thank the Proteomics Facility at the Vermont Genetics Network (Burlington) for completing LC-MS/MS analysis of the prepared samples and A. Howard (University of Vermont, Burlington) for assistance with the statistical analysis. Stipend support for M. Fahey was provided by the Summer Undergraduate Research Fellowship award from the University of Vermont. Research funding was provided by the Alberta Livestock Industry Development Fund (Edmonton, Alberta, Canada). Additional support included use of equipment funded by NIH Grant Numbers 5 P30 RR032135 from the COBRE Program of the National Center for Research Resources (Bethesda, MD) and 8 P30 GM 103498 from the National Institute of General Medical Sciences (Bethesda, MD). The Vermont Genetics Network Proteomics Facility (Burlington, VT) is supported through NIH grant P20GM103449 from the INBRE Program of the National Institute of General Medical Sciences.

\section{REFERENCES}

Boggs, I., B. Hine, G. Smolenski, K. Hettinga, L. Zhang, and T. T. Wheeler. 2016. Proteomics data in support of the quantification of the changes of bovine milk proteins during mammary gland involution. Data Brief 8:52-55. https://doi.org/10.1016/j.dib.2016 .05.013.

Eigel, W. N., C. J. Hofmann, B. A. Chibber, J. M. Tomich, T. W. Keenan, and E. T. Mertz. 1979. Plasmin-mediated proteolysis of casein in bovine milk. Proc. Natl. Acad. Sci. USA 76:2244-2248.

Green, K. A., B. S. Nielsen, F. J. Castellino, J. Rømer, and L. R. Lund. 2006. Lack of plasminogen leads to milk stasis and premature mammary gland involution during lactation. Dev. Biol. 299:164-175.

Hernández-Castellano, L. E., A. M. Almeida, M. Ventosa, A. V. Coelho, N. Castro, and A. Arguello. 2014. The effect of colostrum intake on blood plasma proteome profile in newborn lambs: low abundance proteins. BMC Vet. Res. 10:85-94. https://doi.org/10 .1186/1746-6148-10-85.

Hussein, H. A., K. A. E.-H. A. El-Razik, A. M. Gomaa, M. K. Elbayoumy, K. A. Abdelrahman, and H. I. Hosein. 2018. Milk amyloid A as a biomarker for diagnosis of subclinical mastitis in cattle. Vet. World 11:34-41. https://doi.org/10.14202/vetworld.2018.34-41.

Inman, J. L., C. Robertson, J. D. Mott, and M. J. Bissell. 2015. Mammary gland development: Cell fate specification, stem cells and the microenvironment. Development 142:1028-1042. https://doi.org/ 10.1242/dev.087643.

Isobe, N., H. Kubota, A. Yamasaki, and Y. Yoshimura. 2011. Lactoperoxidase activity in milk is correlated with somatic cell count in 
dairy cows. J. Dairy Sci. 94:3868-3874. https://doi.org/10.3168/ jds.2010-4133.

Koh, Y. Q., H. N. Peiris, K. Vaswani, F. B. Almughlliq, S. Meier, C. R. Burke, J. R. Roche, C. B. Reed, B. J. Arachchige, S. Reed, and M. D. Mitchell. 2018. Proteome profiling of exosomes derived from plasma of heifers with divergent genetic merit for fertility. J. Dairy Sci. 101:6462-6473. https://doi.org/10.3168/jds.2017-14190.

Korhonen, H. 1977. Antimicrobial factors in bovine colostrum. Agric. Food Sci. 49:434-447. https://doi.org/10.23986/afsci.71956.

Kussendrager, K. D., and A. C. M. van Hooijdonk. 2000. Lactoperoxidase: Physico-chemical properties, occurrence, mechanism of action and applications. Br. J. Nutr. 84(Suppl. 1):S19-S25. https:// doi.org/10.1017/S0007114500002208.

Le, A., L. D. Barton, J. T. Sanders, and Q. A. Zhang. 2011. Exploration of bovine milk proteome in colostral and mature whey using an ion-exchange approach. J. Proteome Res. 10:692-704. https:// doi.org/10.1021/pr100884z.

Lu, D. D., and S. S. Nielsen. 1993. Isolation and characterization of native bovine milk plasminogen activators. J. Dairy Sci. 76:33693383. https://doi.org/10.3168/jds.S0022-0302(93)77675-4.

Lu, J., E. Antunes Fernandes, A. E. Páez Cano, J. Vinitwatanakhun, S. Boeren, T. van Hooijdonk, A. van Knegsel, J. Vervoort, and K. A. Hettinga. 2013. Changes in milk proteome and metabolome associated with dry period length, energy balance, and lactation stage in postparturient dairy cows. J. Proteome Res. 12:3288-3296. https://doi.org/10.1021/pr4001306.

Mi, H., Q. Dong, A. Muruganujan, P. Gaudet, S. Lewis, and P. D. Thomas. 2010. PANTHER version 7: Improved phylogenetic trees, orthologs and collaboration with the Gene Ontology Consortium. Nucleic Acids Res. 38(Suppl. 1):D204-D210. https://doi.org/10 $.1093 /$ nar/gkp1019.

Miles, L. A., N. Baik, H. Bai, H. P. Makarenkova, W. B. Kiosses, S. Krajewski, F. J. Castellino, A. Valenzuela, N. M. Varki, B. M. Mueller, and R. J. Parmer. 2018. The plasminogen receptor, $\mathrm{Plg}-\mathrm{RKT}$, is essential for mammary lobuloalveolar development and lactation. J. Thromb. Haemost. 16:919-932. https://doi.org/ 10.1111/jth.13988.

Miller, N., L. Delbecchi, D. Petitclerc, G. F. Wagner, B. G. Talbot, and P. Lacasse. 2006. Effect of stage of lactation and parity on mammary gland cell renewal. J. Dairy Sci. 89:4669-4677. https:// doi.org/10.3168/jds.S0022-0302(06)72517-6.

Nissen, A., P. H. Andersen, E. Bendixen, K. L. Ingvartsen, and C. M. Røntved. 2017. Colostrum and milk protein rankings and ratios of importance to neonatal calf health using a proteomics approach. J. Dairy Sci. 100:2711-2728. https://doi.org/10.3168/jds.2016-11722.

Nissen, A., E. Bendixen, K. L. Ingvartsen, and C. M. Røntved. 2012. In-depth analysis of low abundant proteins in bovine colostrum using different fractionation techniques. Proteomics 12:2866-2878. https://doi.org/10.1002/pmic.201200231.

Precetti, A. S., M. P. Oria, and S. S. Nielsen. 1997. Presence in bovine milk of two protease inhibitors of the plasmin system. J. Dairy Sci. 80:1490-1496. https://doi.org/10.3168/jds.S0022-0302(97)76077 $-6$.
Reinhardt, T. A., R. E. Sacco, B. J. Nonnecke, and J. D. Lippolis. 2013. Bovine milk proteome: Quantitative changes in normal milk exosomes, milk fat globule membranes and whey proteomes resulting from Staphylococcus aureus mastitis. J. Proteomics 82:141-154. https://doi.org/10.1016/j.jprot.2013.02.013.

Samuel, M., D. Chisanga, M. Liem, S. Keerthikumar, S. Anand, C.S. Ang, C. G. Adda, E. Versteegen, M. Jois, and S. Mathivanan. 2017. Bovine milk-derived exosomes from colostrum are enriched with proteins implicated in immune response and growth. Sci. Rep. 7:5933. https://doi.org/10.1038/s41598-017-06288-8.

Silanikove, N. 2016. Transcellular route as the most probable explanation for the presence of plasminogen in mammal's milk. J. Theor. Biol. 395:221-226.

Stelwagen, K., E. Carpenter, B. Haigh, A. Hodgkinson, and T. T. Wheeler. 2009. Immune components of bovine colostrum and milk. J. Anim. Sci. 87(suppl_13):3-9. https://doi.org/10.2527/jas.2008 -1377 .

Tacoma, R., J. Fields, D. B. Ebenstein, Y. W. Lam, and S. L. Greenwood. 2016. Characterization of the bovine milk proteome in earlylactation Holstein and Jersey breeds of dairy cows. J. Proteomics 130:200-210. https://doi.org/10.1016/j.jprot.2015.09.024.

Tacoma, R., S. L. Gelsinger, Y. W. Lam, R. A. Scuderi, D. B. Ebenstein, A. J. Heinrichs, and S. L. Greenwood. 2017. Exploration of the bovine colostrum proteome and effects of heat treatment time on colostrum protein profile. J. Dairy Sci. 100:9392-9401. https:// doi.org/10.3168/jds.2017-13211.

Thomas, P. D., M. J. Campbell, A. Kejariwal, H. Mi, B. Karlak, R. Daverman, K. Diemer, A. Muruganujan, and A. Narechania. 2003. PANTHER: A library of protein families and subfamilies indexed by function. Genome Res. 13:2129-2141. https://doi.org/10.1101/ gr.772403.

Weaver, D. M., J. W. Tyler, D. C. VanMetre, D. E. Hostetler, and G. M. Barrington. 2000. Passive transfer of colostral immunoglobulins in calves. J. Vet. Intern. Med. 14:569-577. https://doi.org/10 $.1111 /$ j.1939-1676.2000.tb02278.x.

Zhang, L., S. Boeren, J. A. Hageman, T. van Hooijdonk, J. Vervoort, and K. Hettinga. 2015. Bovine milk proteome in the first 9 days: Protein interactions in maturation of the immune and digestive system of the newborn. PLoS One 10:e0116710. https://doi.org/10 .1371/journal.pone.0116710.

Zwirzitz, A., M. Reiter, R. Skrabana, A. Ohradanova-Repic, O. Majdic, M. Gutekova, O. Cehlar, E. Petrovcikova, E. Kutejova, G. Stanek, H. Stockinger, and V. Leksa. 2018. Lactoferrin is a natural inhibitor of plasminogen activation. J. Biol. Chem. 293:8600-8613. https://doi.org/10.1074/jbc.RA118.003145.

\section{ORCIDS}

M. A. Steele $\odot$ https://orcid.org/0000-0001-6941-6205

S. L. Greenwood (® https://orcid.org/0000-0003-0654-6103 